Article

\title{
Extraction Optimization, Purification, Antioxidant Activity, and Preliminary Structural Characterization of Crude Polysaccharide from an Arctic Chlorella sp.
}

\author{
Hong Song, Meilin He, Chuankun Gu, Dong Wei, Yuqi Liang, Junmei Yan and Changhai Wang * \\ Jiangsu Provincial Key Laboratory of Marine Biology, College of Resources and Environmental Science, \\ Nanjing Agricultural University, 1 Tongwei Road, Nanjing 210095, China; songhong8912@163.com (H.S.); \\ hemeilin@njau.edu.cn (M.H.); 2016103007@njau.edu.cn (C.G.); 13260980201@163.com (D.W.); \\ 18931330996@163.com (Y.L.); Ninglyq@163.com (J.Y.) \\ * Correspondence: chwang@njau.edu.cn; Tel.: +86-25-8439-6680
}

Received: 16 January 2018; Accepted: 4 March 2018; Published: 9 March 2018

\begin{abstract}
The arctic strain of Chlorella sp. (Chlorella-Arc) exists in the coldest and driest arctic ecosystems, and it is a new resource of active polysaccharides. The extraction of crude polysaccharide from Chlorella-Arc was optimized using the response surface methodology. A crude polysaccharide yield of approximately $9.62 \pm 0.11 \%$ dry weight was obtained under these optimized conditions. Three fractions (P-I, P-II, and P-III) were present after purification by 2-diethylaminoethanol Sepharose Fast Flow and Sephadex G-100 chromatography. The P-IIa fraction demonstrated significant antioxidant activities. Moreover, P-IIa was an $\alpha$ - and $\beta$-type heteropolysaccharide with a pyran group and contained variable amounts of rhamnose, arabinose, glucose, and galactose based on fourier-transform infrared spectroscopy, high-performance liquid chromatography, and ${ }^{1} \mathrm{H}$ and ${ }^{13} \mathrm{C}$ nuclear magnetic resonance imaging. Production of high amounts of polysaccharide may allow further exploration of the microalgae Chlorella-Arc as a natural antioxidant.
\end{abstract}

Keywords: arctic Chlorella sp.; polysaccharide; antioxidant activity; preliminary structural characterization

\section{Introduction}

Oxidation is an essential biological process for energy production in many living organisms. However, abundant reactive oxygen species are produced in vivo during some oxidative reactions. These oxygen species can react with macromolecules, leading to cellular damage [1]. Some studies have reported the health benefit of a diet rich in antioxidants, which can protect an organism against the damage caused by radicals. Natural antioxidants from seaweeds play an important role in protecting against various diseases and aging processes [2]. Moreover, antioxidant activity has been reported for polysaccharides of numerous genera of algae, including Spirulina, Chlorella, Ahnfeltiopsis, Colpomenia, Halymenia, Laurencia, and Padina [3-5]. The detected antioxidant compounds in these and other seaweeds have potential applications as immunomodulators, antitumor and anti-inflammatory agents, and antioxidants [5-8]. Over the last years, the natural sources of antioxidant extracts from seaweeds have been progressively studied and well-developed in many countries. Seaweeds polysaccharide have been considered to scavenge superoxide radicals, peroxyl radicals, nitric radicals, (1,1-diphenyl-2-picrylhydrazyl radical, DPPH) radicals, ferric reducing antioxidant power, and chelate ferrous ions. It was suggested that polysaccharide derived from marine sources such as seaweeds may have the potential to be used in the food and pharmaceutical industries [8]. The presence of sulfate groups in seaweed polysaccharides was suggested to play an important role in enhancing the antioxidant activities $[9,10]$. 
Chlorella, which belongs to the phylum Chlorophyta, is a genus of single-celled green alga. It is a source of polysaccharides, amino acids, vitamins, fatty acids, and minerals, exemplifying the high nutritional value of green algae $[4,11,12]$. The extraction yields and bioactivities of polysaccharides vary among the different Chlorella species. $\mathrm{Hu}$ et al. extracted polysaccharides from Chlorella pyrenoidosa using the supercritical carbon dioxide method through an orthogonal experiment (L16 $\left(4^{5}\right)$ and obtained 16 extracts (highest yield of approximately 7.78\%)). Almost all of the extracts displayed significant anti-radical (1,1-diphenyl-2-picrylhydrazyl radical, DPPH) activities, varying from $29.67 \pm 0.29 \%$ to $54.16 \pm 4.49 \%$ [4]. Erick et al. reported that the extraction yield of Chlorella pyrenoidosa was approximately $15 \%$ by hot aqueous extraction and showed that a hot water extract of Chlorella pyrenoidosa was an immunomodulator [11]. The polysaccharide of Chlorella vulgaris displayed high immunomodulatory activity, with approximately $6.06 \%$ obtained using hot water extraction [13]. Qi et al. reported an extracted polysaccharide yield of $13.10 \%$ from Chlorella ellipsoidea, which showed high immunomodulatory activity [14]. Most studies of the bioactivity of polysaccharides extracted from Chlorella have focused on antitumor and immune activities, instead of antioxidant activity.

The arctic is the coldest and driest region on the Earth. Arctic microalgae have special physiological and biochemical characteristics [15]. These microalgae exist in arctic ecosystems that are a rich resource for the development of active substances, including polysaccharides with special application value. There have been some reports of polar microalgae and their extracellular polysaccharides. These substances protect organisms within ice floes from ice-crystal damage, buffer against $\mathrm{pH}$ and salinity changes, and ameliorate other chemical stresses. These substances are significant in arctic ecosystems [16]. However, little is known about intracellular polysaccharides and their biological potential. To the best of our knowledge, no publication has described the optimization of polysaccharide extraction from polar microalgae and examined their antioxidant activity. Moreover, polar algae tolerate low temperatures and are suitable for outdoor cultivation at low temperatures [17]. Therefore, an investigation of extracted polysaccharides from polar microalgae may provide basic data for the future application of large-scale cultivation of these algae at low temperatures.

This study aimed to evaluate the extraction of crude polysaccharides from the polar microalgae Chlorella-Arc. A response surface methodology (RSM) was proposed to optimize the effects of water dried to a microalgae powder, extraction temperature, and time on the extraction yield of crude polysaccharide. A structural examination and evaluation of antioxidant activity of Chlorella-Arc polysaccharides were also performed.

\section{Materials and Methods}

\subsection{Materials and Reagents}

2-diethylaminoethanol (DEAE) Sepharose Fast Flow was obtained from GE Healthcare (Beijing, China). Sephadex G-100 chromatography and standard monosaccharides (analytical grade of glucose, xylose, galactose, rhamnose, sucrose, and fructose), were purchased from Shanghai Baomanbio technology co., LTD (Shanghai, China). Dextran T-500 (ultra pure) was provided by Sigma (Shanghai, China). Bovine serum albumin (ultra pure) and coomassie brilliant blue (ultra pure) were obtained from Beijing Solarbio technology co., LTD (Beijing, China). The other analytical grade reagents: acetone, chloroform, n-butanol, $\mathrm{NaCl}, \mathrm{Na}_{2} \mathrm{HPO}_{4}, \mathrm{NaH}_{2} \mathrm{PO}_{4}, \mathrm{H}_{2} \mathrm{SO}_{4}$, phenol, ethanol, DPPH radical, $\mathrm{H}_{2} \mathrm{O}_{2}$, pyrogallol, $\mathrm{HCl}$, trifluoroacetic acid (TFA), ascorbic acid ( $\mathrm{Vc}$ ), $\mathrm{BaCl}_{2}$, gelatin, $\mathrm{K}_{2} \mathrm{SO}_{4}$, trichloroacetic acid (TCA), $\mathrm{KNO}_{3}, \mathrm{~K}_{2} \mathrm{HPO}_{4}, \mathrm{MgSO}_{4} \cdot 7 \mathrm{H}_{2} \mathrm{O}, \mathrm{Ca}\left(\mathrm{NO}_{3}\right)_{2}$, biotin, vitamin $\mathrm{B}_{12}$, thiamin $\left(\mathrm{B}_{1}\right)$, $\mathrm{FeSO}_{4} \cdot 7 \mathrm{H}_{2} \mathrm{O}, \mathrm{Na}_{2} \mathrm{EDTA}, \mathrm{MnCl}_{2} \cdot 4 \mathrm{H}_{2} \mathrm{O}, \mathrm{CoSO}_{4} \cdot 7 \mathrm{H}_{2} \mathrm{O}, \mathrm{CuSO} \cdot 5 \mathrm{H}_{2} \mathrm{O}, \mathrm{H}_{3} \mathrm{BO}_{3},\left(\mathrm{NH}_{4}\right)_{6} \mathrm{Mo}_{7} \mathrm{O}_{24} \cdot 4 \mathrm{H}_{2} \mathrm{O}$, $\mathrm{NiSO}_{4} \cdot 6 \mathrm{H}_{2} \mathrm{O}, \mathrm{NH}_{4} \mathrm{VO}_{3}$ and $\mathrm{ZnSO}_{4} \cdot 7 \mathrm{H}_{2} \mathrm{O}$ were purchased from Nanjing Sode Test Equipment Co., LTD (Nanjing, China). 


\subsection{Algae Growth Conditions}

Chlorella-Arc cells were isolated from glacier melt water collected near China's Yellow River Station in the Ny-Alesund area $\left(78^{\circ} 55^{\prime} \mathrm{N} ; 11^{\circ} 56^{\prime} \mathrm{E}\right.$, Spitsbergen Island). Chlorella-Arc cells were obtained from the polar research laboratory of the State Oceanic Administration of Polar Science of China. Its rbcL sequence was sent to Genebank and blasted (Genebank number: KM514914). The algae was pre-cultured in Bourelly medium [18] at $3^{\circ} \mathrm{C}$ and the cells were inoculated into fresh Bourelly medium. It was grown in an Erlenmeyer flask (volume: $2 \mathrm{~L}$ ), temperature was set to $15^{\circ} \mathrm{C}$ and a light intensity of 5000 lux with a light/dark cycle of $12 \mathrm{~h}: 12 \mathrm{~h}$ with continuous bubbling air. The algal cells were grown for 20 days to reach the early stationary phase with a cell density of $3.46 \times 10^{7}$ cells $/ \mathrm{mL}$. The biomass was collected by centrifugation at $8000 \mathrm{rpm}$ for $15 \mathrm{~min}$, and then was vacuum freeze-dried for $24 \mathrm{~h}$ to obtain microalgae powder.

\subsection{Polysaccharide Extraction}

Crude polysaccharide was extracted using the hot water extraction method [19]. Before the extraction, water and dried microalgae powder were mixed, and the mixtures were treated using ultrasonic rod crasher (JY92-II, Ningbo Scientz biotechnology Co., Ltd., Ningbo, China) at $1000 \mathrm{~W}$ for $10 \mathrm{~min}$ to destroy cell walls, and this procedure was performed on ice. Three factors were optimized to obtain the maximum polysaccharide yield: the ratio of water to dried microalgae powder, extraction temperature, and extraction time. Each pretreated sample mentioned above was extracted under ratio of water to dried algae powder (volume: dry weight, mL:mg; 10:1, 20:1, 30:1, 40:1, and 50:1), extraction temperature $\left(50,60,70,80,90^{\circ} \mathrm{C}\right)$ and extraction time $(1,2,3,4,5 \mathrm{~h})$. One factor is changed, while the other factors keep constant in each experiment.

After extraction, the mixtures were centrifuged at $8000 \mathrm{rpm}$ for $10 \mathrm{~min}$. The supernatants were collected, and the polysaccharide precipitated by the addition of pure ethanol. The pellets were refluxed three times to remove any lipids with a mixture of acetone and chloroform $(1: 3, v / v)$. Residual proteins were removed using Sevage reagent (a 4:1 $v / v$ mixture of chloroform and n-butanol) [20]. The protein precipitate was separated by centrifugation ( $4000 \mathrm{rpm}$ for $15 \mathrm{~min}$ ) and discarded, and the supernatants were collected and dialyzed in 14,000 Da dialysis bags for $48 \mathrm{~h}$ and precipitated by the addition of ethanol. The pellets were dried using a lyophilizer (Beijing Boyikang experimental instrument co., Ltd., Beijing, China) for $6 \mathrm{~h}$ to obtain crude polysaccharide powder. The crude polysaccharide yield (\%) was calculated as:

The crude polysaccharide yield $\%=\frac{\text { Crude polysaccharide weight }(\mathrm{mg})}{\text { Dried microalgae powder }(\mathrm{mg})} \times 100 \%$

\subsection{RSM Experimental Design}

The main factors affecting polysaccharide yield (\%) were the ratio of water to dried microalgae powder (mL:g), extraction temperature $\left({ }^{\circ} \mathrm{C}\right)$, and extraction time (h). These three factors at their three levels are shown in Table 1.

Table 1. Experiment factors and levels for Box-Behnken design (BBD).

\begin{tabular}{cccccc}
\hline Factors & & & \multicolumn{3}{c}{ Levels } \\
\cline { 4 - 6 } & Code & Actual & $\mathbf{- 1}$ & $\mathbf{0}$ & $\mathbf{1}$ \\
\hline Ratio of water to dried microalgae powder $(\mathrm{mL} / \mathrm{g})$ & $\mathrm{X}_{1}$ & $\mathrm{x}_{1}$ & 30 & 40 & 50 \\
Extraction temperature $\left({ }^{\circ} \mathrm{C}\right)$ & $\mathrm{X}_{2}$ & $\mathrm{x}_{2}$ & 70 & 80 & 90 \\
Extraction time $(\mathrm{h})$ & $\mathrm{X}_{3}$ & $\mathrm{x}_{3}$ & 2 & 3 & 4 \\
\hline
\end{tabular}

\subsection{Purification of Crude Chlorella-Arc Polysaccharide}

The crude polysaccharides ( 2 g) were dissolved in $400 \mathrm{~mL}$ phosphate-buffered solution (PBS) $(\mathrm{pH}=7.4)$. Three milliliter of this solution was loaded onto a chromatography column $(1.2 \mathrm{~cm} \times$ 
$20 \mathrm{~cm}$ ) with DEAE Sepharose Fast Flow and sequentially eluted with PBS $(\mathrm{pH}=7.4)$ and a gradient of $0-2.0 \mathrm{M}$ sodium chloride at a flow rate of $1.0 \mathrm{~mL} / \mathrm{min}$. Each fraction $(5 \mathrm{~mL})$ of the eluate was collected. The carbohydrate content of each fraction was determined using the phenol-sulfuric acid method [21], and the protein content of fractions was determined using the Coomassie brilliant blue method [22]. The collected fractions were designated P-I, P-II, and P-III. Freeze-dried P-II fractions were dissolved in PBS ( $\mathrm{pH}=7.4)$. Five milliliters of the solution were loaded onto a Sephadex G-100 column $(1.6 \mathrm{~cm} \times$ $100 \mathrm{~cm}$ ) and eluted with $0.3 \mathrm{M}$ sodium chloride at a flow rate of $0.5 \mathrm{~mL} / \mathrm{min}$. Each $5-\mathrm{mL}$ fraction was processed as described above.

\subsection{DPPH Radical Scavenging Assay}

DPPH radical scavenging activity was measured as previously described [23]. Briefly, $2.0 \mathrm{~mL}$ of DPPH solution $(0.004 \% w / v$ dehydrated alcohol) was added to $2.0 \mathrm{~mL}$ of polysaccharides dissolved in distilled water at different concentrations $(0.25,0.5,0.75,1.0,3.0,5.0,7.0$, and $10.0 \mathrm{mg} / \mathrm{mL})$. The mixtures were shaken and left standing for $30 \mathrm{~min}$ at $25{ }^{\circ} \mathrm{C}$ in the dark. The absorbance of each was measured at $517 \mathrm{~nm}$. A lower absorbance of the reaction mixture indicated higher free radical scavenging activity. The ability to scavenge the DPPH radical was calculated using the following equation:

$$
\text { DPPH radical scavenging effect }(\%)=\left[1-\frac{\mathrm{A}-\mathrm{A}_{0}}{\mathrm{~A}_{1}}\right] \times 100 \%
$$

where $A$ is the absorbance of the sample in DPPH at $517 \mathrm{~nm}, \mathrm{~A}_{0}$ is the absorbance of the sample in dehydrated alcohol at $517 \mathrm{~nm}$ (does not contain DPPH supplement), and $A_{1}$ is the $A_{517}$ of DPPH in distilled water.

\subsection{Hydroxyl Radical Scavenging Assay}

The assay was done as previously described [24] with some modifications. Briefly, $2.0 \mathrm{~mL}$ of $6.0 \mathrm{mM} \mathrm{FeSO}_{4}$ and $2.0 \mathrm{~mL}$ of $6.0 \mathrm{mM}$ ethanol salicylate were added to $2.0 \mathrm{~mL}$ of polysaccharide solution $(0.25,0.5,0.75,1.0,3.0,5.0,7.0$, and $10.0 \mathrm{mg} / \mathrm{mL})$, then $2.0 \mathrm{~mL}$ of $6.0 \mathrm{mM} \mathrm{H}_{2} \mathrm{O}_{2}$ was added finally to start the reactions and incubated at $37^{\circ} \mathrm{C}$ for $30 \mathrm{~min}$. Fenton reaction produces hydroxyl radicals: $\mathrm{Fe}^{2+}+\mathrm{H}_{2} \mathrm{O}_{2} \rightarrow \mathrm{Fe}^{3+}+\mathrm{OH}^{-}+\cdot \mathrm{OH}$, then $\cdot \mathrm{OH}$ reacts with salicylate solution. The products could be measured at $510 \mathrm{~nm}$. The scavenging effect on hydroxyl radical was calculated (\%) as:

$$
\text { Hydroxyl radical scavenging effect }(\%)=\left[\frac{\mathrm{A}_{1}-\mathrm{A}}{\mathrm{A}_{1}}\right] \times 100 \%
$$

where $A_{1}$ is the absorbance of the blank and $A$ is the final absorbance of each sample (the polysaccharides or ascorbic acid).

\subsection{Superoxide Radical Scavenging Assay}

Superoxide radical scavenging activity was measured as previously described [20] with slight modifications. Briefly, $2.5 \mathrm{~mL}$ of $50 \mathrm{mM}$ Tris- $\mathrm{HCl}$ buffer ( $\mathrm{pH} 8.2)$ was maintained at $25^{\circ} \mathrm{C}$ for $20 \mathrm{~min}$, $4 \mathrm{~mL}$ of polysaccharide solution $(0.25,0.5,0.75,1.0,3.0,5.0,7.0$, and $10.0 \mathrm{mg} / \mathrm{mL})$, and $0.6 \mathrm{~mL}$ of $25 \mathrm{mM}$ pyrogallol solution was added. The mixture was incubated at $25^{\circ} \mathrm{C}$ for $5 \mathrm{~min}$ and then $1 \mathrm{~mL}$ of $8.0 \mathrm{mM} \mathrm{HCl}$ solution was added to each mixture to terminate the reaction. The absorbances of the mixtures were recorded at $299 \mathrm{~nm}$. The scavenging effect on superoxide radical was calculated (\%) as:

$$
\text { Superoxide radical scavenging effect }(\%)=\left[1-\frac{\mathrm{A}-\mathrm{A}_{0}}{\mathrm{~A}_{1}}\right] \times 100 \%
$$


where $A_{0}$ is the absorbance of the blank (Tris- $\mathrm{HCl}$ buffer instead of the sample), $\mathrm{A}_{1}$ is the final absorbance of a sample, and A is the background absorbance (Tris- $\mathrm{HCl}$ buffer instead of pyrogallol solution).

\subsection{Ultraviolet-Visible (UV-Vis) and Fourier-Transform Infrared (FT-IR) Analyses}

The UV-Vis absorption spectra of samples were recorded using a UV-visible spectrophotometer (Beijing Purkinje General Instrument Co., Ltd., Beijing, China) in the spectral scan range of $200-400 \mathrm{~nm}^{-1}$ at room temperature.

The presence of various functional groups and compounds in the polysaccharide extracts were detected in the FTIR spectra as described previously [25]. The dried samples were ground with $\mathrm{KBr}$ powder and then pressed into a pellet for FT-IR using a Nicolet IR200 apparatus (Thermo Nicolet Corporation, Madison, WI, USA) measurement at a frequency range of $400-4000 \mathrm{~cm}^{-1}$ at a resolution of $4 \mathrm{~cm}^{-1}$.

\subsection{Monosaccharide Compositional Analysis}

P-IIa was hydrolyzed in $4 \mathrm{~mol} / \mathrm{L}$ TFA for $2 \mathrm{~h}$ at $110^{\circ} \mathrm{C}$ in a sealed glass tube. After removing the residual acid, the hydrolyzates were further analyzed to determine the monosaccharide composition using a model 1200 high-performance liquid chromatography (HPLC) apparatus (Agilent Technologies, Palo Alto, CA, USA), a Prevail Carbohydrate ES column-W250 $\times 4.6 \mathrm{~mm} 5 \mu \mathrm{m}$ (Alltech, Nicholasville, KY, USA), and an ELSD 3300 detector (Alltech, Nicholasville, KY, USA) at a flow rate of $1.0 \mathrm{~mL} / \mathrm{min}$. The mobile phases (A and B) were acetonitrile and distilled water, respectively. The column was equilibrated in $75 \%$ mobile phase $\mathrm{A}$ as previously described [26] with the following modifications: 0-10 min linear gradient of 65\% A, 10-20 min linear gradient of $50 \% \mathrm{~A}, 20-25 \mathrm{~min}$ of $50 \% \mathrm{~A}, 25-26 \mathrm{~min}$ linear gradient of $75 \% \mathrm{~A}$, and $26-35 \mathrm{~min}$ of $75 \% \mathrm{~A}$.

\subsection{Nuclear Magnetic Resonance (NMR) Spectroscopy}

${ }^{1} \mathrm{H}$ and ${ }^{13} \mathrm{C}$ NMR spectra were recorded with an Avance DRX600 spectrometer (Bruker, Beijing, China). The extracted polysaccharide were dissolved in deuterium $\left(\mathrm{D}_{2} \mathrm{O}, 99.9 \%\right)$ prior to the analysis, and exchangeable protons were substituted by deuterium after time lyophilization procedures [27]. Chemical shifts are shown in ppm.

\subsection{Analysis of Sulfate-Group Content}

The sulfate-group $\left(-\mathrm{SO}_{3} \mathrm{H}\right)$ content of polysaccharides was determined by the $\mathrm{BaCl}_{2}$-gelatin turbidity method $[28,29]$. In a typical procedure, $0.3 \%$ gelatin solution was prepared in hot water $70{ }^{\circ} \mathrm{C}$ and stored at $4{ }^{\circ} \mathrm{C}$ overnight. Two grams of $\mathrm{BaCl}_{2}$ was dissolved in gelatin solution and allowed to stand for $2-3 \mathrm{~h}$ at $25^{\circ} \mathrm{C}$. The preparation of standard solution of $\mathrm{K}_{2} \mathrm{SO}_{4}$ : dried the $\mathrm{K}_{2} \mathrm{SO}_{4}$ powder under $105{ }^{\circ} \mathrm{C}$, then accurately weighed $217.8 \mathrm{mg} \mathrm{K}_{2} \mathrm{SO}_{4}$ and dissolved in $200 \mathrm{~mL} 1 \mathrm{~mol} / \mathrm{L} \mathrm{HCl}$. The preparation of polysaccharide solution: $8 \mathrm{mg}$ extracted polysaccharide was hydrolyzed in $3 \mathrm{~mL}$ $1 \mathrm{~mol} / \mathrm{L} \mathrm{HCl}$ for $5 \mathrm{~h}$ at $105{ }^{\circ} \mathrm{C}$ in a sealed glass tube [28]. About $0.20 \mathrm{~mL}$ of $\mathrm{K}_{2} \mathrm{SO}_{4}$ stand solution (polysaccharide solution) was added to $3.8 \mathrm{~mL}$ of TCA and $1 \mathrm{~mL}$ of $\mathrm{BaCl}_{2}$-gelatin reagent, and the mixture was allowed to stand for 10-20 min. A blank was prepared with $0.2 \mathrm{~mL}$ of water instead of $\mathrm{K}_{2} \mathrm{SO}_{4}$ stand solution. The released barium sulfate suspension was measured at $360 \mathrm{~nm}$ by UV-visible spectrophotometer. The standard curve was shown in Figure S1.

\subsection{Statistical Analysis}

Results were expressed as Mean \pm SD from three independent experiments. Statistical analysis was performed using Design-Expert (Version 8.0.6 Trial) and SPSS (Version 20.0) statistical software. Data were analyzed using ANOVA followed by SNK-q test, a significant difference in values at $p<0.05$. 


\section{Results and Discussion}

\subsection{Selection of Extraction Optimization Factors}

The effect of the water/powder ratio on the yield of crude polysaccharide is presented in Figure 1a. The extraction process was carried out at 10:1, 20:1, 30:1, 40:1, and 50:1, while the other two extraction factors were set as follows: extraction temperature $80{ }^{\circ} \mathrm{C}$ and extraction time $2 \mathrm{~h}$. The crude polysaccharide yield increased from $3.57 \%$ to $7.38 \%$ with ratios increasing from $10: 1$ to 40:1. This might be explained by the fact that constituents can dissolve more effectively in more water, resulting in enhanced diffusivity of the solvent into cells, leading to an increased extraction yield [20,30,31]. A decrease in the extraction yield was observed with an increase in the water:powder ratio to 50:1. Therefore, we selected a ratio of water to dried microalgae powder of 40:1 as optimal.

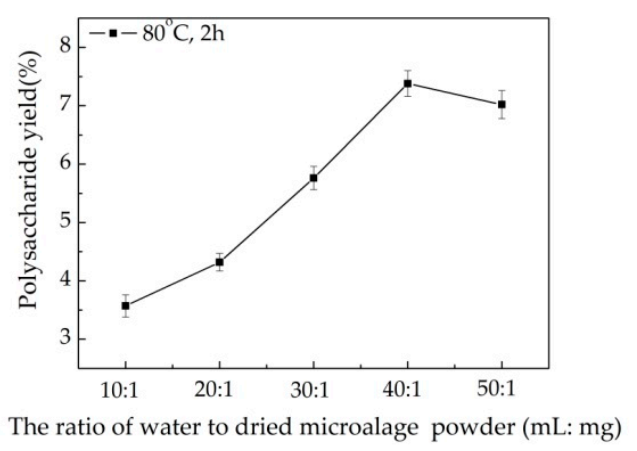

(a)

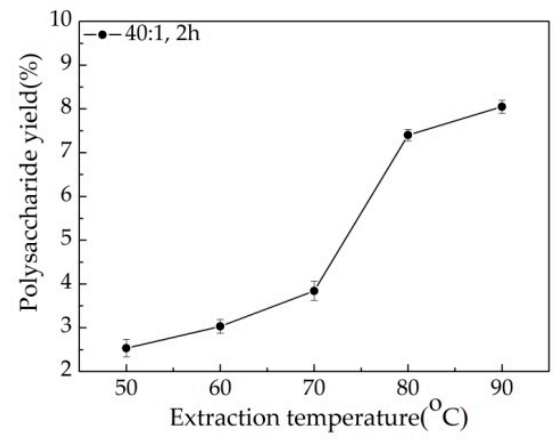

(b)

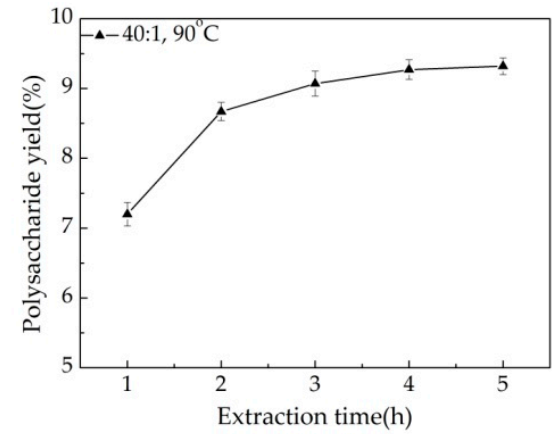

(c)

Figure 1. Effects of the ratio of water to dried algae powder (a) extraction temperature (b) and extraction time (c) on crude Chlorella-Arc polysaccharide extraction yield. Errors bars represent standard error for three replicates.

As shown in Figure 1b, the extraction temperature was another factor that would influence the extraction yield. The extraction process was carried out at 50,60,70,80, and $90^{\circ} \mathrm{C}$, other experimental conditions were as follows: the water/powder ratio 40: 1 and extraction time $2 \mathrm{~h}$. The maximum extraction yield $(8.05 \%)$ was obtained when the temperature was $90{ }^{\circ} \mathrm{C}$. A considerable increase (from $3.84 \%$ to $7.40 \%$ ) in the extraction yield was observed when the temperature increased from 70 to $80^{\circ} \mathrm{C}$. An increase in the extraction temperature resulted in the minimization of mass-transfer resistance [31]. Therefore, polysaccharides yields obtained at a higher temperature were significantly higher than those obtained at a lower temperature. Temperatures for the extraction of algae polysaccharides commonly range from 70 to $90{ }^{\circ} \mathrm{C}$, but the extraction temperature has been extended above $90{ }^{\circ} \mathrm{C}$ [32]. High temperatures, however, may affect the yield and physiological activity of polysaccharides [3,30]. Based on these results, the temperature for extraction of polysaccharides in Chlorella-Arc was maintained below $90{ }^{\circ} \mathrm{C}$. 
The yield of crude polysaccharide extract increased as the extraction time was extended beyond $3 \mathrm{~h}$ (Figure 1c), when the water/powder ratio and extraction temperature were fixed at $40: 1$ and $90{ }^{\circ} \mathrm{C}$. The maximum extraction yield $(9.32 \%)$ was observed at $5 \mathrm{~h}$, but this time resulted in only a small increase in yield above that obtained at $3 \mathrm{~h}(9.07 \%)$. The extraction time is as important as the extraction temperature for polysaccharide yield $[3,20]$. From an industrialization perspective, an increase in time increases the cost of the extraction process. Therefore, $3 \mathrm{~h}$ was considered the optimal extraction time.

Based on this single-factor study, we adopted a water:powder ratio of 40:1, extraction temperature of $80^{\circ} \mathrm{C}$ and extraction time of $3 \mathrm{~h}$ as optimal for the RSM experiments.

\subsection{Box-Behnken Design (BBD) to Optimize Polysaccharide Extraction}

The response values for the 17 trials are shown in Table 2. The second-order polynomial model used can be characterized by the equation below (5).

$$
Y=8.42+0.77 X_{1}+0.27 X_{2}+0.49 X_{3}+0.022 X_{1} X_{2}+0.082 X_{1} X_{3}-0.023 X_{2} X_{3}-0.059 X_{1}^{2}-1.73 X_{2}^{2}-0.40 X_{3}^{2}
$$

Table 2. Box-Behnken Design (BBD) and the response values for extraction yields of crude polysaccharide.

\begin{tabular}{cccccc}
\hline \multirow{2}{*}{ Run } & $\mathbf{X}_{\mathbf{1}}(\mathbf{m L} \mathbf{\text { g}})$ & $\mathbf{X}_{\mathbf{2}}\left({ }^{\circ} \mathbf{C}\right)$ & $\mathbf{X}_{\mathbf{3}}(\mathbf{h})$ & \multicolumn{2}{c}{ Crude Polysaccharides Yield(\%) } \\
\cline { 5 - 6 } & & & 3 & Actual & Predicted \\
\hline 1 & 40 & 80 & 3 & 8.35 & 8.42 \\
2 & 30 & 80 & 4 & 7.25 & 7.07 \\
3 & 30 & 70 & 3 & 2.59 & 2.66 \\
4 & 30 & 90 & 3 & 7.99 & 8.01 \\
5 & 40 & 80 & 3 & 8.50 & 8.42 \\
6 & 40 & 80 & 3 & 8.61 & 8.42 \\
7 & 40 & 80 & 3 & 8.34 & 8.42 \\
8 & 50 & 90 & 3 & 9.65 & 9.58 \\
9 & 40 & 70 & 4 & 4.20 & 4.31 \\
10 & 50 & 80 & 4 & 8.86 & 8.76 \\
11 & 50 & 70 & 3 & 4.16 & 4.14 \\
12 & 50 & 80 & 2 & 7.45 & 7.63 \\
13 & 40 & 70 & 2 & 3.04 & 2.87 \\
14 & 40 & 80 & 3 & 8.30 & 8.42 \\
15 & 40 & 90 & 4 & 9.07 & 9.24 \\
16 & 40 & 90 & 2 & 8.84 & 8.73 \\
17 & 30 & 80 & 2 & 6.17 & 6.17 \\
\hline
\end{tabular}

Results of the ANOVA are shown in Table S1. A model $F$-value of 261.59 with a very low $p$-value $(<0.0001)$ indicated that the model could be used to predict the crude polysaccharide extract yield [30,33]. In addition, the values of R-squared (0.9970), adj R-squared (0.9932), and pred R-squared (0.9647) revealed that the polynomial model was sufficiently accurate and generally available $[3,34]$. A low coefficient of variation $(2.59 \%)$ clearly indicated significant precision and reliability of the experimental results [31].

\subsection{Analysis of the Response Surface}

The effects of different factors on crude polysaccharide extraction were evaluated using threedimensional (3D) graphs (Figure 2a-c). Two factors were depicted in the 3D response surface and two-dimensional (2D) contour plots, while another factor was held at zero. The shapes of the contour plots suggested the significance of the mutual interactions between the factors [31,34]. In the present study, the three factors each had a positive impact on the crude polysaccharide yield. Using Design-Expert, the optimum ratio of water to dried microalgae powder, extraction temperature, and extraction time to obtain crude polysaccharides were determined to be $47: 1,88^{\circ} \mathrm{C}$, 
and $3 \mathrm{~h}$, respectively. The maximum predicted crude polysaccharide yield was $9.81 \%$, and the experimental yield of crude polysaccharide was $9.62 \pm 0.11 \%,(n=3)$, which agreed with the predicted value. Shi et al. [32] obtained an polysaccharide extract yield of $4.48 \%$ from Chlorella pyrenoidosa. By optimizing the extraction of polysaccharides from this organism using the hot water extraction method, Hu et al. [4] obtained the highest reported polysaccharide yield of $7.78 \%$. Tabarsa et al. reported a polysaccharide yield of $6.06 \%$ from Chlorella vulgaris following optimization of extraction conditions [13]. Qi et al. extracted Chlorella ellipsoidea polysaccharide and reported the yield was about $13.1 \%$. The crude polysaccharide yield of our Chlorella-Arc approximately $9.62 \pm 0.11 \%$ dry weight was obtained [14]. Therefore, Chlorella-Arc is a promising source of polysaccharides and its conspicuous polysaccharide yields offer an appreciable advantage over other Chlorella sp.

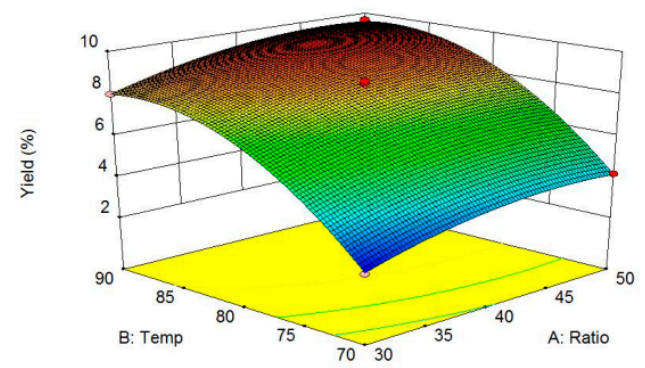

(a)

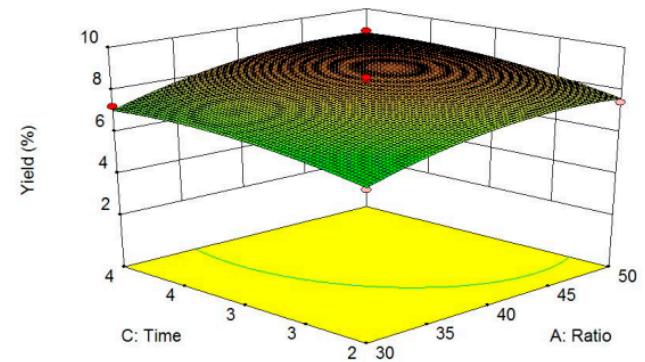

(b)



(c)

Figure 2. Response surface and contour plots for the effects of different parameters on Chlorella-Arc polysaccharide yields. (a) Ratio of water to dried microalgae powder and extraction temperature, with the extraction time held constant at $3 \mathrm{~h}$. (b) Ratio of water to dried microalgae powder and extraction time, with the extraction temperature held at $80^{\circ} \mathrm{C}$. (c) Extraction temperature and extraction time, with the ratio of water to dried microalgae powder fixed at 40:1.

\subsection{Purification of Crude Chorella-Arc Polysaccharide}

Following DEAE Sepharose Fast Flow chromatography purification, the crude polysaccharide from Chlorella-Arc was determined to contain three main fractions: P-I, P-II, and P-III (Figure 3a). P-II was further purified by Sephadex G-100 column chromatography and found to contain two peaks: P-IIa and P-IIb (Figure 3b). As shown in Figure 3c, P-IIa gave a single and symmetrical peak in the Sephadex G-100 column chromatograms, indicating that it represented a homogeneous and chromatographically pure polysaccharide [33]. The UV-Vis spectrum of P-IIa is shown in Figure 3d. The UV-Vis spectrum indicated that there were no optical absorption peaks at $260-280 \mathrm{~nm}$. Therefore, P-IIa contains little proteins or nucleic acids, since proteins and nucleic acids absorb light at 260 and $280 \mathrm{~nm}$, respectively. In addition, commasie brilliant blue staining (Figure 3a) confirmed low limit detection of proteins in the fraction. 


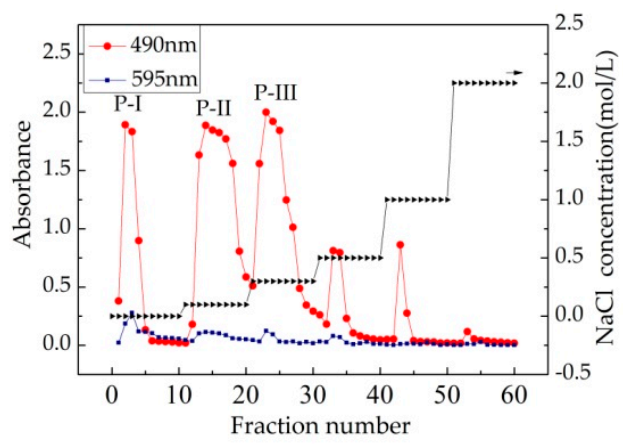

(a)

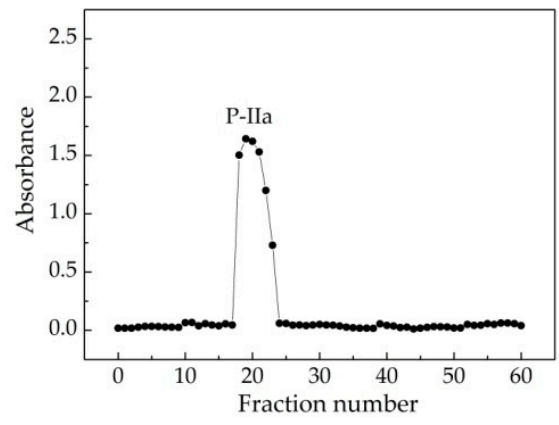

(c)

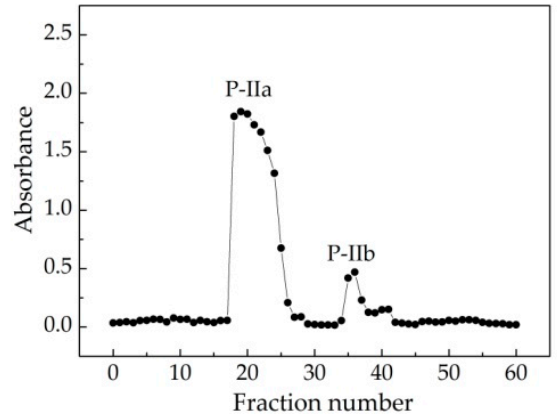

(b)



(d)

Figure 3. Isolation and physicochemical analysis of the polysaccharides extracted from Chlorella-Arc. (a) DEAE-Sepharose Fast Flow chromatogram elution curve of Chlorella-Arc polysaccharides. Fractions were collected and examined for metachromasia using phenol- $\mathrm{H}_{2} \mathrm{SO}_{4}(-\bullet-)$ and Coomassie brilliant blue (-m-). There were three major fractions in the crude Chlorella-Arc polysaccharide (P-I, P-II, and P-III). (b) Sephadex G-100 chromatogram elution profile of P-II; (c) Sephadex G-100 chromatogram elution profile of P-IIa; (d) UV-Vis spectrum of P-IIa

\subsection{Antioxidant Properties}

Polysaccharides are abundant antioxidants. Microalgae polysaccharides have been widely reported as displaying antioxidant activities [4,24]. These previous reports lead us to check the antioxidant activities of the polysaccharides extracted from Chlorella-Arc. In order to evaluate the antioxidant activity of Chlorella-Arc polysaccharides, it was compared to the known standard antioxidant ascorbic acid.

\subsubsection{Scavenging Effects of Polysaccharide on DPPH Radical}

DPPH radicals are stable free radicals that show a maximum absorption at $517 \mathrm{~nm}$ in methanol. The scavenging effect of antioxidants on DPPH radicals is a result of their proton-donating ability [35]. In DPPH radical tests, antioxidants can reduce the stable radical DPPH to yellow-colored diphenylpicryl hydrazine [20]. Based on this principle, the antioxidant activity of a substance can be measured by its ability to scavenge DPPH free radical. Figure 4a depicts the DPPH scavenging abilities of different concentrations of crude polysaccharide and ascorbic acid. The scavenging effect of the crude polysaccharide increased with increasing concentrations ranging from 0.25 to $10.0 \mathrm{mg} / \mathrm{mL}$. The crude polysaccharide removed $49.10 \pm 2.50 \%$ of DPPH radical at a concentration of $5.0 \mathrm{mg} / \mathrm{mL}$. With higher concentrations, no further effect on DPPH radical was apparent. However, ascorbic acid displayed a stronger ability to scavenge DPPH radical. Specifically, ascorbic acid scavenged more DPPH radical (from $51.50 \pm 2.30 \%$ to $82.00 \pm 1.90 \%$ ) as its concentration increased from 0.25 to $1.0 \mathrm{mg} / \mathrm{mL}$. Hu et al. [4] reported the extraction of crude polysaccharide from Chlorella pyrenoidosa in an orthogonal experiment $\left(\mathrm{L}_{16}\left(4^{5}\right)\right)$. Almost all of the 16 extracts $(10.0 \mathrm{mg} / \mathrm{mL})$ showed high 
DPPH radical scavenging effects ranging from $29.67 \pm 0.29 \%$ to $54.16 \pm 4.49 \%$. Chaiklahan et al. [3] extracted crude polysaccharide from Spirulina sp. at different temperatures $\left(50,70,80\right.$, and $\left.90{ }^{\circ} \mathrm{C}\right)$. At a concentration of $2.5 \mathrm{mg} / \mathrm{mL}$, the DPPH radical scavenging effects ranged from $6.30 \pm 2.10 \%$ to $31.00 \pm$ $4.00 \%$. Therefore, the crude polysaccharide from Chlorella-Arc obtained in this study removed DPPH free radicals similar to the polysaccharide from Spirulina sp. Ben Hafsa et al. reported water-soluble polysaccharides extracted from microalgae Isochrysis galbana (PEA) and Nannochloropsis oculata (PEB), showing a concentration dependent DPPH.radical scavenging activity. At concentration of $10 \mathrm{mg} / \mathrm{mL}$, both PEA and PEB exhibit an antioxidant activity of 41.45 and 59.07\% [36]. Custódio et al. indicated that organic extracts from $N$. oculata had also antioxidant properties with $\mathrm{IC}_{50}$ values between 4.93 and $7.31 \%$ [37]. Moreover, Balavigneswaran et al. reported that an ethanol soluble polysaccharidic extracts from I. galbana was active against DPPH (almost 40\%) at $10 \mathrm{mg} / \mathrm{mL}$ [20].

\subsubsection{Scavenging Effects of Polysaccharide on Hydroxyl Radical}

Hydroxyl radicals in cells can easily cross cell membranes at specific sites, react with most biological macromolecules, and cause tissue damage and cell death. Thus, removing hydroxyl radicals is very important for the protection of living systems [38]. Presently, the hydroxyl radical scavenging effects of the crude extract were not as strong as ascorbic acid at any of the concentrations tested (Figure $4 \mathrm{~b}$ ). The scavenging effect of ascorbic acid on hydroxyl radical reached a plateau of 96.00 $\pm 2.30 \%$ at a concentration of $1.0 \mathrm{mg} / \mathrm{mL}$. The ability of the crude polysaccharide to scavenge hydroxyl radical was concentration-dependent (Figure 4b). A significant increase in the scavenging activity of the tested crude polysaccharide was observed from $0.25-7.0 \mathrm{mg} / \mathrm{mL}$. At a concentration of $7.0 \mathrm{mg} / \mathrm{mL}$, the hydroxyl radical scavenging effect was $80.20 \pm 2.70 \%$. The crude polysaccharide displayed a slow increase in its ability to scavenge hydroxyl radical, with maximum activity of $85.60 \pm 3.20 \%$ obtained at $10.0 \mathrm{mg} / \mathrm{mL}$. Balavigneswaran et al. [20] extracted crude polysaccharide from I. galbana $(20.0 \mathrm{mg} / \mathrm{mL})$ and reported hydroxyl radical scavenging effects of approximately $60 \%$. $\mathrm{Xu}$ et al. [39] reported a polysaccharide extracted from Sphallerocarpus gracilis with a hydroxyl radical scavenging effect of approximately $70 \%$ at $5.0 \mathrm{mg} / \mathrm{mL}$. A chemical modification of polysaccharide is the form of a sulfated derivative produced a similar hydroxyl radical scavenging effect $(80 \%)$ as the crude polysaccharide used in this study. Xia et al. reported polysaccharides extracted from marine diatom Odontella aurita was active against hydroxyl radical, at $10 \mathrm{mg} / \mathrm{mL}$ reaching the removal effect of $83.54 \pm 6.71 \%$ [40]. Zhao et al. purified different polysacchareide fractions of F1, F2, and F3 from Laminaria japonica, and found all the fractions exhibited obvious scavenging activity on the hydroxyl radical in a concentration-dependent manner, at $5 \mathrm{mg} / \mathrm{mL}$, reaching $35 \%, 60 \%$, and $65 \%$ scavenging efficiency [41]. Our results indicate that the crude polysaccharide from Chlorella-Arc has significantly higher antiradical activities than previously reported polysaccharide extracts at a dose of $7.0-10.0 \mathrm{mg} / \mathrm{mL}$.

\subsubsection{Scavenging Effects of the Polysaccharide Extract on Superoxide Radical}

Superoxide radicals are oxidants present in most organisms and the source of free radical formed in vivo. Superoxide radicals and their derivatives damage DNA and cell membranes [42]. The effects of superoxide radical scavenging of the crude polysaccharide and ascorbic acid are shown in Figure 4c. The scavenging ability of ascorbic acid increased quickly at concentrations between $0.25 \mathrm{mg} / \mathrm{mL}$ and $5.0 \mathrm{mg} / \mathrm{mL}$, whereas this increase slowed down at concentrations above $5.0 \mathrm{mg} / \mathrm{mL}$. At a concentration of $5.0 \mathrm{mg} / \mathrm{mL}$, the scavenging effect of ascorbic acid on superoxide radical was $94.00 \pm 1.70 \%$. In comparison, the crude polysaccharide showed less of a scavenging effect than ascorbic acid. At $5.0 \mathrm{mg} / \mathrm{mL}$, the effect of the polysaccharide on superoxide radical was $32.10 \pm 1.20 \%$. Above $5.0 \mathrm{mg} / \mathrm{mL}$, the increased concentration had no effect on superoxide radical. The extracted polysaccharide and a chemically modified sulfated derivative from Sphallerocarpus gracilis [39] showed superoxide radical scavenging effects of approximately $50 \%$ and $70 \%$, respectively. Balavigneswaran et al. [20] extracted crude polysaccharide from Isochrysis galbana 
$(5.0 \mathrm{mg} / \mathrm{mL})$ and reported that the corresponding superoxide radical scavenging effect was about $42 \%$. Moreover, Sun et al. isolated polysaccharides (IPSI-A, IPSI-B, and IPSII) from the marine microalgae I. galbana with the abilities of scavenging superoxide radicals of $33.8 \%, 32.3 \%$, and $53.5 \%$ at $3.2 \mathrm{mg} / \mathrm{mL}$ [43]. The crude polysaccharide from Chlorella-Arc showed less activity in scavenging superoxide radical than some other polysaccharides reported and less of an effect on superoxide radical than on DPPH and hydroxyl free radical.

Based on these results, a concentration of $5.0 \mathrm{mg} / \mathrm{mL}$ was selected for further analysis. Table 3 shows the scavenging effects of Chlorella-Arc polysaccharides on DPPH, hydroxyl, and superoxide radical at concentrations of $5.0 \mathrm{mg} / \mathrm{mL}$. Ascorbic acid showed higher antioxidant activities for these radical than Chlorella-Arc polysaccharides, and P-IIa showed greater scavenging effects than other Chlorella-Arc polysaccharides. The scavenging effects of P-IIa on DPPH, hydroxyl, and superoxide radical were $62.20 \pm 1.20 \%, 72.10 \pm 1.50 \%$, and $42.20 \pm 1.60 \%$. Shi et al. reported the biological activities of polysaccharide isolated from Enteromorpha prolifera (PE) are of insufficient potential for a range of purposes in the food and pharmaceutical industries. For instance, at $4 \mathrm{mg} / \mathrm{mL}$ the removal of DPPH, hydroxyl, and superoxide radical by PE reached $11.3 \%, 30.0 \%$ and $28.7 \%$ [44]. Chen et al. extracted C. pyrenoidosa polysaccharides (CPP) using different concentrations of ethanol for precipitation, and found CPP85 showed a great antioxidant activity at $2 \mathrm{mg} / \mathrm{mL}$ with the removal of DPPH, hydroxyl, and superoxide radical reaching $15 \%, 52 \%$, and $55 \%$. However, CPP70 exhibited stronger scavenging activity against superoxide, DPPH and hydroxyl radicals, when compared with CPP85 [24]. Many variables may affect the antioxidant activities of polysaccharides, including their molecular weight, monosaccharide composition, conformation, degree, and sulfate distribution pattern $[23,45]$. Therefore, a promising Chlorella-Arc polysaccharides and its conspicuous antioxidant activity deserved further investigation.

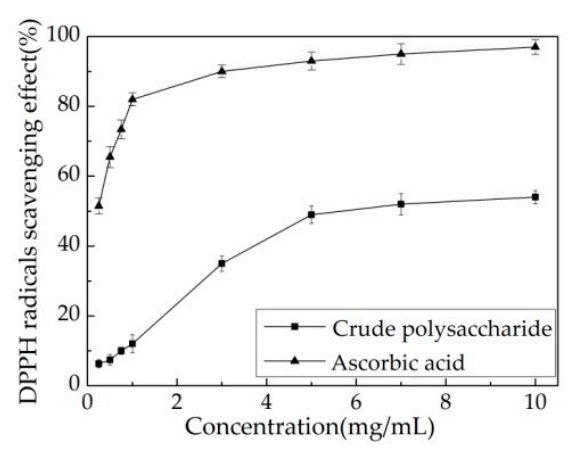

(a)

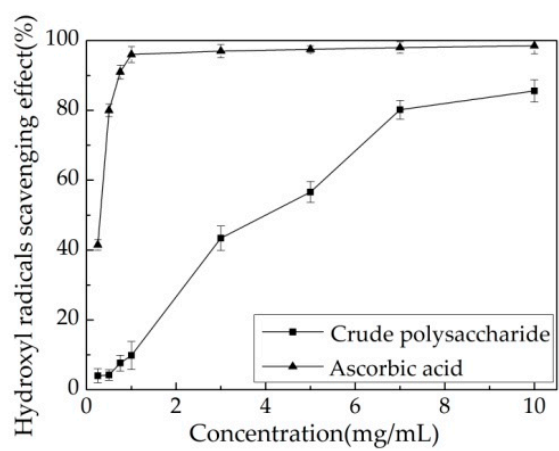

(b)

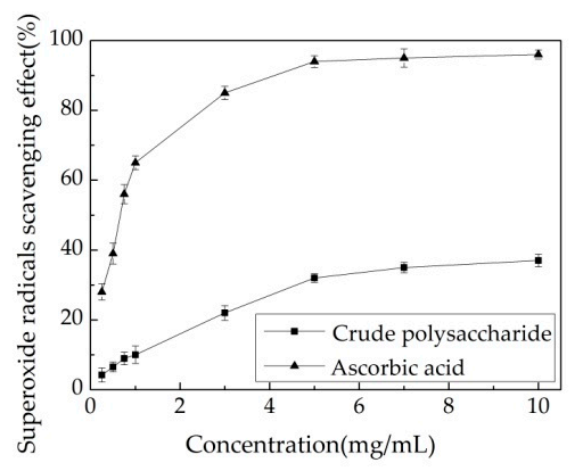

(c)

Figure 4. Antioxidant activities of Chlorella-Arc polysaccharides. (a) Scavenging effects on DPPH radical. (b) Scavenging effects on hydroxyl radical. (c) Scavenging effects on superoxide radical. Errors bars represent standard errors from three replicates. 
Table 3. Antioxidant activity of Chlorella-Arc polysaccharides at $5.0 \mathrm{mg} / \mathrm{mL}$.

\begin{tabular}{cccc}
\hline \multirow{2}{*}{ Sample } & \multicolumn{3}{c}{ Antioxidant Activity (\%) } \\
\cline { 2 - 4 } & DPPH Radical & Hydroxyl Radical & Superoxide Radical \\
\hline Crude polysaccharide & $49.10 \pm 2.50^{\mathrm{c}}$ & $56.60 \pm 2.50^{\mathrm{d}}$ & $32.10 \pm 1.20^{\mathrm{c}}$ \\
P-I & $42.30 \pm 1.70^{\mathrm{b}}$ & $45.10 \pm 2.10^{\mathrm{b}}$ & $23.10 \pm 1.30^{\mathrm{b}}$ \\
P-III & $30.80 \pm 1.20^{\mathrm{a}}$ & $34.90 \pm 1.20^{\mathrm{a}}$ & $20.20 \pm 1.50^{\mathrm{a}}$ \\
P-II & $55.40 \pm 1.30^{\mathrm{d}}$ & $68.30 \pm 2.40^{\mathrm{e}}$ & $40.10 \pm 1.40^{\mathrm{d}}$ \\
P-IIa & $60.20 \pm 1.20^{\mathrm{e}}$ & $72.10 \pm 1.50^{\mathrm{f}}$ & $42.20 \pm 1.60^{\mathrm{d}}$ \\
P-IIb & $30.70 \pm 1.10^{\mathrm{a}}$ & $52.20 \pm 1.60^{\mathrm{c}}$ & $31.30 \pm 1.20^{\mathrm{c}}$ \\
Ascorbic acid & $93.00 \pm 2.60^{\mathrm{f}}$ & $97.50 \pm 1.00^{\mathrm{g}}$ & $94.00 \pm 1.70^{\mathrm{e}}$ \\
\hline
\end{tabular}

In each column, different letters above the bars indicate a significant difference in values at $p<0.05$ (ANOVA followed by SNK-q test).

\subsection{FTIR Spectroscopic Characterization}

To obtain structural information, Dextran T-500 and P-IIa were analyzed by FTIR spectroscopy, which can be used to determine the structure of microalgae polysaccharides $[25,46]$. As shown in Figure 5, there were some overlapping peaks near 3400, 2931, 1650, 1459, 1155, and $860 \mathrm{~cm}^{-1}$ in the spectra of both Chlorella-Arc polysaccharides and the glucan standard (Dextran T-500). Different peaks (at 985, 820, and $531 \mathrm{~cm}^{-1}$ ) were observed in the fingerprint of P-IIa. A broad and intense peak around $3400 \mathrm{~cm}^{-1}$ (Dextran T-500: $3407.93 \mathrm{~cm}^{-1}$; P-IIa: $3424.13 \mathrm{~cm}^{-1}$ ) was attributed to the stretching vibration of O-H [47]. A weak peak at $2930 \mathrm{~cm}^{-1}$ (Dextran T-500: $2931.90 \mathrm{~cm}^{-1}$; P-IIa: $2929.70 \mathrm{~cm}^{-1}$ ) showed the stretching and bending vibration of $\mathrm{C}-\mathrm{H}$ in the sugar ring. In addition, the peak at $1652 \mathrm{~cm}^{-1}$ (Dextran T-500: $1649.59 \mathrm{~cm}^{-1}$, P-IIa: $1653.66 \mathrm{~cm}^{-1}$ ) resulted from the stretching vibration in $\mathrm{C}=\mathrm{O}$ and the carboxyl group [48]. The peak around $1455 \mathrm{~cm}^{-1}$ (Dextran T-500: $1459.17 \mathrm{~cm}^{-1}$; P-IIa: $1459.81 \mathrm{~cm}^{-1}$ ) represented $\mathrm{CH}_{2}$ bonding [49,50]. Two stretching peaks near 1155 and $1076 \mathrm{~cm}^{-1}$ were observed for the polysaccharide (Dextran T-500: 1155.70, $1108.10 \mathrm{~cm}^{-1}$; P-IIa: $1153.82,1076.16 \mathrm{~cm}^{-1}$ ), which suggested the presence of the glycosidic linkages $\gamma \mathrm{C}-\mathrm{O}-\mathrm{C}$ and $\mathrm{C}-\mathrm{OH}$ [51]. The peak at $1249.20-1262.80 \mathrm{~cm}^{-1}$ (P-IIa: $1251.57 \mathrm{~cm}^{-1}$ ) was due to the stretching vibration of $\mathrm{S}=\mathrm{O}[29,52]$. The characteristic peaks at approximately 860 and $820 \mathrm{~cm}^{-1}$ indicated both an $\alpha$ and $\beta$-anomeric configuration [53].

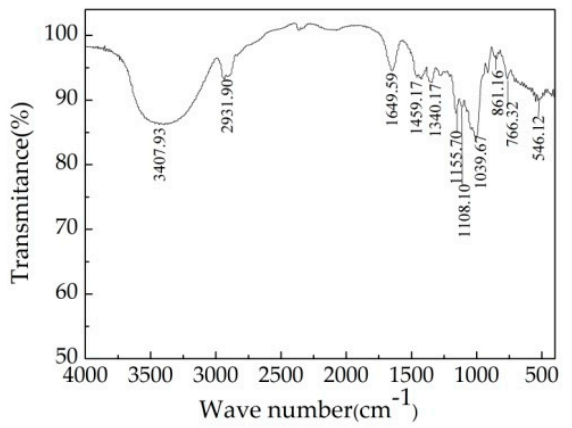

(a)

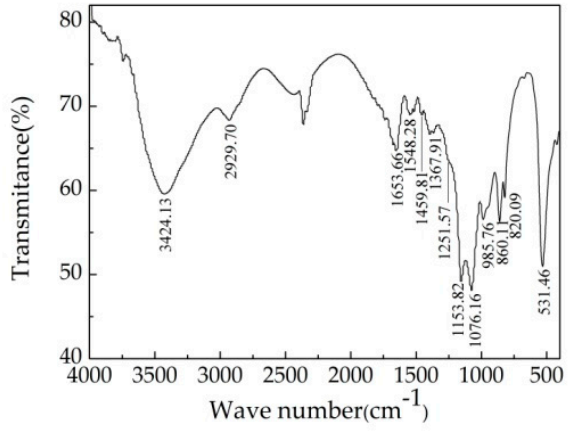

(b)

Figure 5. Fourier-Transform Infrared (FT-IR) spectra of Dextran T-500 (a) and P-IIa (b).

\subsection{Monosaccharide Composition and Sulfate-Group Content Analysis}

The hydrolysate of P-IIa was further analyzed using HPLC to identify monosaccharides. As shown in Figure 6, the major monosaccharide of P-Ila was galactose $(66.00 \%)$ followed by arabinose $(16.32 \%)$, rhamnose $(10.88 \%)$, and glucose $(6.80 \%)$. The molar ratios of galactose:arabinose:rhamnose:glucose was 3.67:1.08:0.66:0.38. Hu et al. isolated a different polysaccharide from C. pyrenoidosa, of which galactose was a major monosaccharide with amounts of glucose, rhamnose, and mannose [54]. The 
polysaccharides of other Chlorella species, including Chlorella vulgaris [13] and Chlorella ellipsoidea [14], were both composed of glucose as the main monosaccharide, but other monosaccharides were varied. The chemical compositions of the microalgal polysaccharide were closely related to Chlorella species [14] and growing conditions, as well as the methods used for extraction. These findings provide a scientific basis for the use of polysaccharides from Chlorella-Arc.

Sulfate-group content analysis showed the presence of sulfate in both crude polysaccharides $(9.96 \pm 0.25 \%)$ and P-IIa (11.58 $\pm 0.17 \%)$. These results were in agreement with previous researches [14] and confirmed the polysaccharide structure with sulfate ester groups (Figure 5b). The presence of $-\mathrm{OSO}_{3} \mathrm{H}$ in the polysaccharide could activate the hydrogen atom of the anomeric carbon. The higher activated capacity of the group, the hydrogen atom will have stronger donating capacity [39]. This might be one of the most important reasons that P-IIa acquiring a better antioxidant activity than crude polysaccharide (as shown in Table 3).

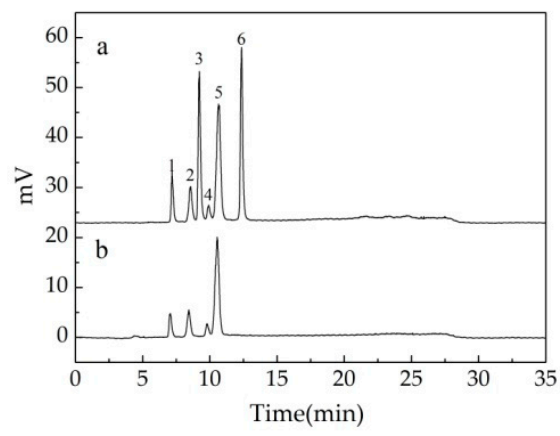

Figure 6. HPLC chromatogram of standard monosaccharides and hydrolyzed P-IIa. (a) Standard monosaccharides (1: rhamnose, 2: arabinose, 3: fructose, 4: glucose, 5: galactose, 6: sucrose). (b) HPLC chromatogram of hydrolyzed P-IIa.

\subsection{NMR Spectra Analysis}

NMR spectroscopy was used to complete the structural characterization of P-IIa. Polysaccharides in the ${ }^{1} \mathrm{H}$ NMR spectra (Figure 7a) typically show crowding in the range of 83.0 to $5.0 \mathrm{ppm}[53,55]$. Chemical shifts from $\delta 3.4$ to $4.0 \mathrm{ppm}$ were considered related to protons present at C-2-C-6. In the anomeric region of the ${ }^{1} \mathrm{H}$ NMR spectrum of P-IIa, four main signals were apparent at $\delta 5.19,5.05,4.95$, and $4.83 \mathrm{ppm}$. These were both higher and lower than $5.0 \mathrm{ppm}$, indicating the presence of both $\alpha$ and $\beta$-configurations $[53,56]$. This agreed with the FT-IR spectrum analysis. The anomeric carbons characteristic of polysaccharides in the ${ }^{13} \mathrm{C}$ NMR spectra show crowding from $\delta 90$ to $110 \mathrm{ppm}$ [57]. The signals at $\delta 95$ to $101 \mathrm{ppm}$ corresponded to $\alpha$-anomeric carbons, and the signals at $\delta 101$ to $105 \mathrm{ppm}$ corresponded to $\beta$-anomeric carbons in the ${ }^{13} \mathrm{C}$ NMR spectrum [56], consistent with the ${ }^{1} \mathrm{H} N M R$ spectrum. As shown in Figure $7 \mathrm{~b}$, the presence of C-1 signals ( $893.46-103.87 \mathrm{ppm})$ also indicated that the sugar residues were all in the pyran ring, as the resonance of the furan ring should be approximately $8107-109 \mathrm{ppm}[55,57]$. Based on the available data in the literature, the H-1 signal at $\delta 5.19 \mathrm{ppm}$ was likely due to ${ }^{1} \mathrm{H}$ resonance of $\alpha$-galactose residues, and the $\mathrm{C}-1$ signal at $\delta 99.03 \mathrm{ppm}$ in the ${ }^{13} \mathrm{C}$ NMR spectra supported this explanation. The $\mathrm{H}-1$ signal at $\delta 4.06 \mathrm{ppm}$ and $\mathrm{C}-1$ signal at $\delta 101.43$ ppm suggested that the polysaccharide contained $\beta$-arabinose residues [56], and the H-1 signal at $\delta 4.83 \mathrm{ppm}$ and $\mathrm{C}-1$ signal at $\delta 103.87 \mathrm{ppm}$ indicated an $\beta$-anomeric configuration for $(1 \rightarrow 4)$-linked $\beta$-D-glucopyranosyl units [22,55]. 


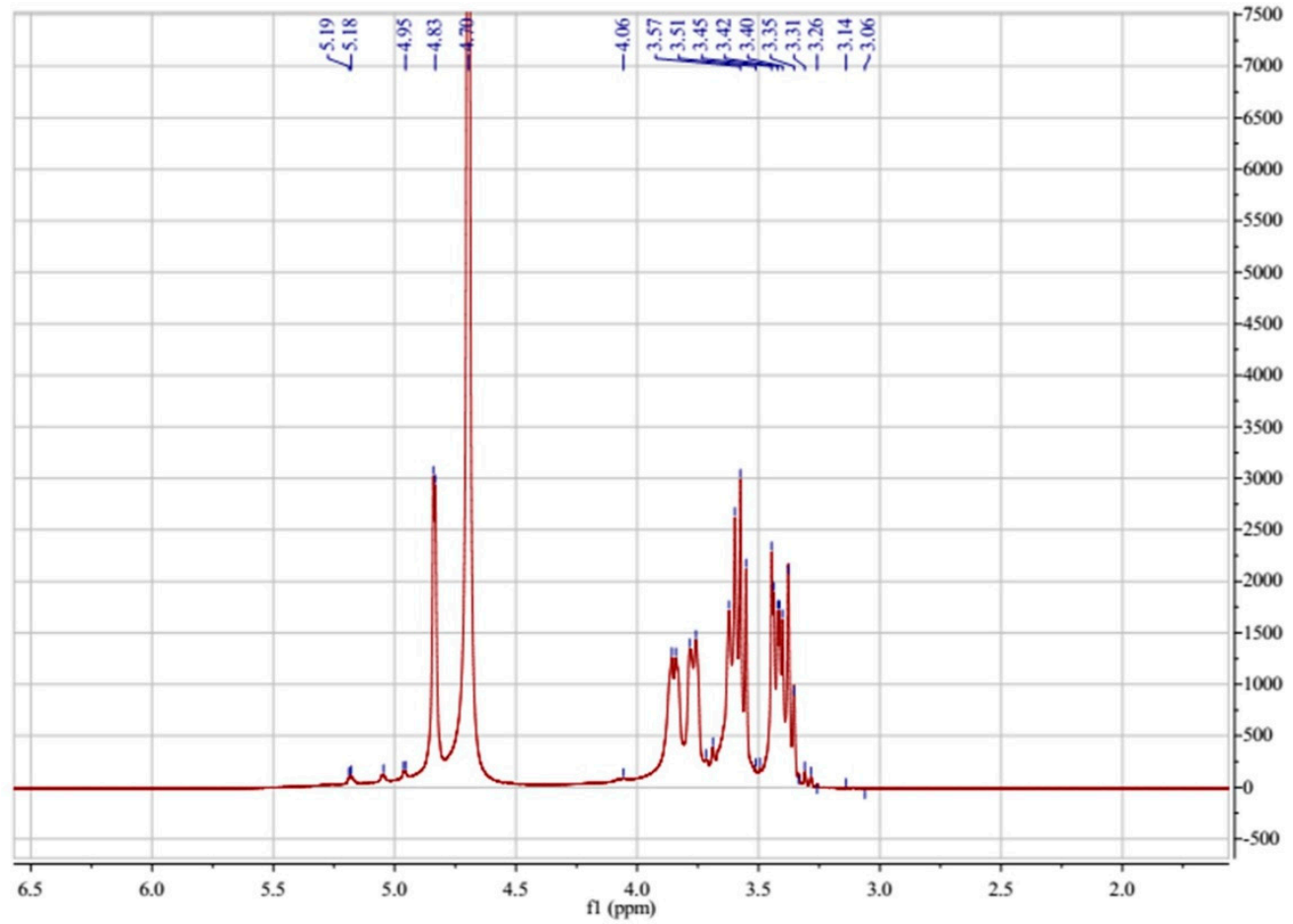

(a)

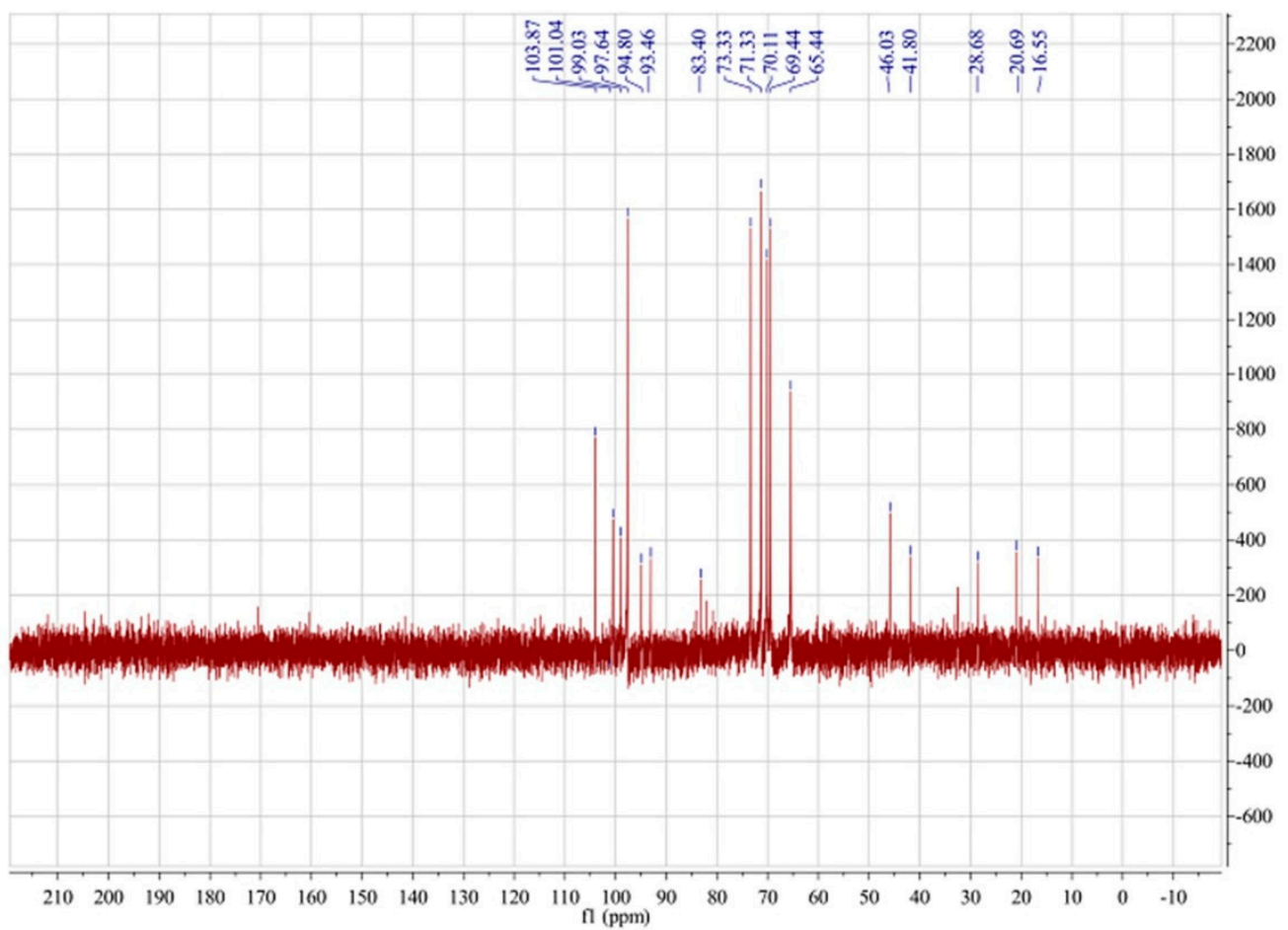

(b)

Figure 7. ${ }^{1} \mathrm{H}$ NMR spectrum (a) and ${ }^{13} \mathrm{C}$ NMR spectrum (b) of P-IIa. 


\section{Conclusions}

Extraction of crude polysaccharide from an arctic Chlorella strain, Chlorella-Arc, was optimized using RSM, purification, assessment of antioxidant activity, and preliminary structural characterization. Under the optimized conditions, Chlorella-Arc yielded a crude polysaccharide of approximately $9.62 \pm 0.11 \%$ dry weight. After purification, three fractions (P-I, P-II, and P-III) were obtained. Antioxidant tests in vitro indicated greater antioxidant activity of P-IIa than other Chlorella-Arc polysaccharide fractions. The structural analysis revealed that P-IIa is a heteropolysaccharide with a pyran group and is composed mainly of rhamnose, arabinose, glucose, and galactose. These findings provide a scientific basis for the use of polysaccharides from Chlorella-Arc.

Supplementary Materials: The following are available online at www.mdpi.com/2073-4360/10/3/292/s1, Figure S1: Standard curve for determination of sulfate group content in microalgae polysaccharides by $\mathrm{BaCl} 2-$ gelatin method. Regression equation is: $\mathrm{Y}=0.31416 \mathrm{x}+0.04545, \mathrm{R}=0.99647$, Figure S2: UV-VIS spectrum of P-IIa, Table S1: ANOVA of the experimental results of the BBD.

Acknowledgments: The financial support from National Natural Science Foundation of China (31500318), and Natural Science Foundation of Jiangsu Province (BK20140713) for this research is gratefully acknowledge.

Author Contributions: H.S. and M.H. conceived and designed the experiments; H.S., D.W., and C.G. performed the experiments; Y.L. and J.Y. analyzed the data; H.S. wrote the paper; C.W. revised the manuscript.

Conflicts of Interest: The authors declare no conflict of interest.

\section{References}

1. Moskovitz, J.; Yim, M.B.; Chock, P.B. Free radicals and disease. Arch. Biochem. Biophys. 2002, 397, $354-359$. [CrossRef] [PubMed]

2. Zubia, M.; Robledo, D.; Freile-Pelegrin, Y. Antioxidant activities in tropical marine macroalgae from the Yucatan Peninsula, Mexico. J. Appl. Phycol. 2007, 19, 449-458. [CrossRef]

3. Chaiklahan, R.; Chirasuwan, N.; Triratana, P.; Loha, V.; Tia, S.; Bunnag, B. Polysaccharide extraction from Spirulina sp. and its antioxidant capacity. Int. J. Biol. Macromol. 2013, 58, 73-78. [CrossRef] [PubMed]

4. Hu, Q.; Pan, B.; Xu, J.; Sheng, J.; Shi, Y. Effects of supercritical carbon dioxide extraction conditions on yields and antioxidant activity of Chlorella pyrenoidosa extracts. J. Food Eng. 2007, 80, 997-1001. [CrossRef]

5. Cornish, M.L.; Garbary, D.J. Antioxidants from macroalgae: Potential applications in human health and nutrition. Algae 2010, 25, 155-171. [CrossRef]

6. Ananthi, S.; Raghavendran, H.R.B.; Sunil, A.G.; Gayathri, V.; Ramakrishnan, G.; Vasanthi, H.R. In vitro antioxidant and in vivo anti-inflammatory potential of crude polysaccharide from Turbinaria ornata (marine brown alga). Food Chem. Toxicol. 2010, 48, 187-192. [CrossRef] [PubMed]

7. Xu, S.; Huang, X.; Cheong, K. Recent advances in marine algae polysaccharides: Isolation, structure, and activities. Mar. Drugs 2017, 15, 388. [CrossRef] [PubMed]

8. Roohinejad, S.; Koubaa, M.; Barba, F.J.; Saljoughian, S.; Amid, M.; Greiner, R. Application of seaweeds to develop new food products with enhanced shelf-life, quality and health-related beneficial properties. Food Res. Int. 2017, 99, 1066-1083. [CrossRef] [PubMed]

9. Souza, B.W.; Cerqueira, M.A.; Bourbon, A.I.; Pinheiro, A.C.; Martins, J.T.; Teixeira, J.A.; Vicente, A.A. Chemical characterization and antioxidant activity of sulfated polysaccharide from the red seaweed Gracilaria birdiae. Food Hydrocoll. 2012, 27, 287-292. [CrossRef]

10. Qi, H.; Zhao, T.; Zhang, Q.; Li, Z.; Zhao, Z.; Xing, R. Antioxidant activity of different molecular weight sulfated polysaccharides from Ulva pertusa Kjellm (Chlorophyta). J. Appl. Phycol. 2005, 17, 527-534. [CrossRef]

11. Suárez, E.R.; Kralovec, J.A.; Noseda, M.D.; Ewart, H.S.; Barrow, C.J.; Lumsden, M.D.; Grindley, T.B. Isolation, characterization and structural determination of a unique type of arabinogalactan from an immunostimulatory extract of Chlorella pyrenoidosa. Carbohydr. Res. 2005, 340, 1489-1498. [CrossRef] [PubMed]

12. Yang, F.; Shi, Y.; Sheng, J.; Hu, Q. In vivo immunomodulatory activity of polysaccharides derived from Chlorella pyrenoidosa. Eur. Food Res. Technol. 2006, 224, 225-228. [CrossRef]

13. Tabarsa, M.; Shin, I.-S.; Lee, J.H.; Surayot, U.; Park, W.; You, S. An immune-enhancing water-soluble $\alpha$-glucan from Chlorella vulgaris and structural characteristics. Food Sci. Biotechnol. 2015, 24, 1933-1941. [CrossRef] 
14. Qi, J.; Kim, S.M. Characterization and immunomodulatory activities of polysaccharides extracted from green alga Chlorella ellipsoidea. Int. J. Biol. Macromol. 2017, 95, 106-114. [CrossRef] [PubMed]

15. Sun, M.; Zhao, F.; Shi, M.; Zhang, X.; Zhou, B.; Zhang, Y.; Chen, X. Characterization and biotechnological potential analysis of a new exopolysaccharide from the arctic marine bacterium Polaribacter sp. SM1127. Sci. Rep. 2015, 5, 18435. [CrossRef] [PubMed]

16. Krembsa, C.; Eickenb, H.; Jungea, K.; Deming, J.W. High concentrations of exopolymeric substances in arctic winter sea ice: Implications for the polar ocean carbon cycle and cryoprotection of diatoms. Deep-Sea Res. I 2002, 49, 2163-2181. [CrossRef]

17. Ahn, J.W.; Hwangbo, K.; Lee, S.Y.; Choi, H.G.; Park, Y.I.; Liu, J.R.; Jeong, W.J. A new arctic Chlorella species for biodiesel production. Bioresour. Technol. 2012, 125, 340-343. [CrossRef] [PubMed]

18. Cao, K.; He, M.; Yang, W.; Chen, B.; Luo, W.; Zou, S.; Wang, C. The eurythermal adaptivity and temperature tolerance of a newly isolated psychrotolerant arctic Chlorella sp. J. Appl. Phycol. 2016, 28, 877-888. [CrossRef]

19. Paradossi, G.; Cavalieri, F.; Pizzoferrato, L.; Liquori, A.M. A physico-chemical study on the polysaccharide ulvan from hot water extraction of the macroalga Ulva. Int. J. Biol. Macromol. 1999, 25, 309-315. [CrossRef]

20. Balavigneswaran, C.K.; Sujin Jeba Kumar, T.; Moses Packiaraj, R.; Veeraraj, A.; Prakash, S. Anti-oxidant activity of polysaccharides extracted from Isocrysis galbana using RSM optimized conditions. Int. J. Biol. Macromol. 2013, 60, 100-108. [CrossRef] [PubMed]

21. Dubois, M.; Gilles, K.; Hamilton, J.; Rebers, P.; Smith, F. Colorimetric method for determination of sugars and related substances. Anal. Chem. 1956, 28, 350-356. [CrossRef]

22. Zhang, B.; Xu, J.; Zhang, H.; Zhang, Q.; Lu, J.; Wang, J. Structure elucidation of a polysaccharide from Umbilicaria esculenta and its immunostimulatory activity. PLoS ONE 2016, 11, e0168472. [CrossRef] [PubMed]

23. Sun, H.; Mao, W.; Chen, Y.; Guo, S.; Li, H.; Qi, X.; Chen, Y.; Xu, J. Isolation, chemical characteristics and antioxidant properties of the polysaccharides from marine fungus Penicillium sp. F23-2. Carbohydr. Polym. 2009, 78, 117-124. [CrossRef]

24. Chen, Y.; Liu, X.; Xiao, Z.; Huang, Y.; Liu, B. Antioxidant activities of polysaccharides obtained from Chlorella pyrenoidosa via different ethanol concentrations. Int. J. Biol. Macromol. 2016, 91, 505-509. [CrossRef] [PubMed]

25. Geun Goo, B.; Baek, G.; Jin Choi, D.; Il Park, Y.; Synytsya, A.; Bleha, R.; Ho Seong, D.; Lee, C.G.; Kweon Park, J. Characterization of a renewable extracellular polysaccharide from defatted microalgae Dunaliella tertiolecta. Bioresour. Technol. 2013, 129, 343-350. [CrossRef] [PubMed]

26. Xu, H.; Liang, M.; Xu, L.; Li, H.; Zhang, X.; Kang, J.; Zhao, Q.; Zhao, H. Cloning and functional characterization of two abiotic stress-responsive Jerusalem artichoke (Helianthus tuberosus) fructan 1-exohydrolases (1-FEHs). Plant Mol. Biol. 2014, 87, 81-98. [CrossRef] [PubMed]

27. Dong, X.; Pan, R.; Deng, X.; Chen, Y.; Zhao, G.; Wang, C. Separation, purification, anticoagulant activity and preliminary structural characterization of two sulfated polysaccharides from sea cucumber Acaudina molpadioidea and Holothuria nobilis. Process Biochem. 2014, 49, 1352-1361. [CrossRef]

28. Patankar, M.S.; Oehninger, S.; Barnett, T.; Williams, R.L.; Clark, G.F. A revised structure for fucoidan may explain some of its biological activities. J. Biol. Chem. 1993, 268, 21770-21776. [PubMed]

29. Bhadja, P.; Tan, C.-Y.; Ouyang, J.-M.; Yu, K. Repair effect of seaweed polysaccharides with different contents of sulfate group and molecular weights on damaged HK-2 cells. Polymers 2016, 8, 188. [CrossRef]

30. Zhao, Y.; Shi, Y.; Yang, H.; Mao, L. Extraction of Angelica sinensis polysaccharides using ultrasound-assisted way and its bioactivity. Int. J. Biol. Macromol. 2016, 88, 44-50. [CrossRef] [PubMed]

31. Li, Q.; Yu, N.; Wang, Y.; Sun, Y.; Lu, K.; Guan, W. Extraction optimization of Bruguiera gymnorrhiza polysaccharides with radical scavenging activities. Carbohydr. Polym. 2013, 96, 148-155. [CrossRef] [PubMed]

32. Shi, Y.; Sheng, J.C.; Yang, F.M.; Hu, Q.H. Purification and identification of polysaccharide derived from Chlorella pyrenoidosa. Food Chem. 2007, 103, 101-105. [CrossRef]

33. Chen, J.; Tian, S.; Shu, X.; Du, H.; Li, N.; Wang, J. Extraction, characterization and immunological activity of polysaccharides from Rhizoma gastrodiae. Int. J. Mol. Sci. 2016, 17, 1011. [CrossRef] [PubMed]

34. Wang, J.; Zhao, B.; Wang, X.; Zhang, J. Preparation and characterization of sulfated galactomannan from guar gum: Optimization of reaction conditions by BBD and molecule conformational studies. J. Taiwan Inst. Chem. Eng. 2012, 43, 889-896. [CrossRef]

35. Hu, T.; Liu, D.; Chen, Y.; Wu, J.; Wang, S. Antioxidant activity of sulfated polysaccharide fractions extracted from Undaria pinnitafida in vitro. Int. J. Biol. Macromol. 2010, 46, 193-198. [CrossRef] [PubMed] 
36. Ben Hafsa, M.; Ben Ismail, M.; Garrab, M.; Aly, R.; Gagnon, J.; Naghmouchi, K. Antimicrobial, antioxidant, cytotoxic and anticholinesterase activities of water-soluble polysaccharides extracted from microalgae Isochrysis galbana and Nannochloropsis oculata. J. Serb. Chem. Soc. 2017, 82, 509-522.

37. Custódio, L.; Soares, F.; Pereira, H.; Rodrigues, M.J.; Barreira, L.; Rauter, A.P.; Alberício, F.; Varela, J. Botryococcus braunii and Nannochloropsis oculata extracts inhibit cholinesterases and protect human dopaminergic SH-SY5Y cells from $\mathrm{H}_{2} \mathrm{O}_{2}$-induced cytotoxicity. J. Appl. Phycol. 2014, 27, 839-848. [CrossRef]

38. Yang, J.; Guo, J.; Yuan, J. In vitro antioxidant properties of rutin. LWT Food Sci. Technol. 2008, 41, 1060-1066. [CrossRef]

39. Xu, Y.; Song, S.; Wei, Y.; Wang, F.; Zhao, M.; Guo, J.; Zhang, J. Sulfated modification of the polysaccharide from Sphallerocarpus gracilis and its antioxidant activities. Int. J. Biol. Macromol. 2016, 87, 180-190. [CrossRef] [PubMed]

40. Xia, S.; Gao, B.; Li, A.; Xiong, J.; Ao, Z.; Zhang, C. Preliminary characterization, antioxidant properties and production of chrysolaminarin from marine diatom Odontella aurita. Mar. Drugs 2014, 12, 4883-4897. [CrossRef] [PubMed]

41. Zhao, D.; Xu, J.; Xu, X. Bioactivity of fucoidan extracted from Laminaria japonica using a novel procedure with high yield. Food Chem. 2018, 245, 911-918. [CrossRef] [PubMed]

42. Macdonald, J.; Galley, H.F.; Webster, N.R. Oxidative stress and gene expression in sepsis. Br. J. Anaesth. 2003, 90, 221-232. [CrossRef] [PubMed]

43. Sun, Y.; Wang, H.; Guo, G.; Pu, Y.; Yan, B. The isolation and antioxidant activity of polysaccharides from the marine microalgae Isochrysis galbana. Carbohydr. Polym. 2014, 113, 22-31. [CrossRef] [PubMed]

44. Shi, M.; Wei, X.; Xu, J.; Chen, B.; Zhao, D.; Cui, S.; Zhou, T. Carboxymethylated degraded polysaccharides from Enteromorpha prolifera: Preparation and in vitro antioxidant activity. Food Chem. 2017, 215, 76-83. [CrossRef] [PubMed]

45. Li, H.; Yuan, Q.; Zhou, X.; Zeng, F.; Lu, X. Extraction of Opuntia dillenii Haw. polysaccharides and their antioxidant activities. Molecules 2016, 21, 1612. [CrossRef] [PubMed]

46. Pereira, L.; Amado, A.M.; Critchley, A.T.; van de Velde, F.; Ribeiro-Claro, P.J.A. Identification of selected seaweed polysaccharides (phycocolloids) by vibrational spectroscopy (FTIR-ATR and FT-Raman). Food Hydrocoll. 2009, 23, 1903-1909. [CrossRef]

47. Kanmani, P.; Kumar, R.S.; Yuvaraj, N.; Paari, K.A.; Pattukumar, V.; Arul, V. Production and purification of a novel exopolysaccharide from lactic acid bacterium Streptococcus phocae PI80 and its functional characteristics activity in vitro. Bioresour. Technol. 2011, 102, 4827-4833. [CrossRef] [PubMed]

48. Luo, Q.; Tang, Z.; Zhang, X.; Zhong, Y.; Yao, S.; Wang, L.; Lin, C.; Luo, X. Chemical properties and antioxidant activity of a water-soluble polysaccharide from Dendrobium officinale. Int. J. Biol. Macromol. 2016, 89, $219-227$. [CrossRef] [PubMed]

49. Xu, Y.; Cai, F.; Yu, Z.; Zhang, L.; Li, X.; Yang, Y.; Liu, G. Optimisation of pressurised water extraction of polysaccharides from blackcurrant and its antioxidant activity. Food Chem. 2016, 194, 650-658. [CrossRef] [PubMed]

50. Yang, X.; Wang, R.; Zhang, S.; Zhu, W.; Tang, J.; Liu, J.; Chen, P.; Zhang, D.; Ye, W.; Zheng, Y. Polysaccharides from Panax japonicus C.A. Meyer and their antioxidant activities. Carbohydr. Polym. 2014, 101, 386-391. [CrossRef] [PubMed]

51. Sun, R.C.; Fang, J.M.; Goodwin, A.; Lawther, J.M.; Bolton, A.J. Fractionation and characterization of polysaccharides from abaca fibre. Carbohydr. Polym. 1998, 37, 351-359. [CrossRef]

52. Fimbres-Olivarria, D.; Carvajal-Millan, E.; Lopez-Elias, J.A.; Martinez-Robinson, K.G.; Miranda-Baeza, A.; Martinez-Cordova, L.R.; Enriquez-Ocaña, F.; Valdez-Holguin, J.E. Chemical characterization and antioxidant activity of sulfated polysaccharides from Navicula sp. Food Hydrocoll. 2018, 75, 229-236. [CrossRef]

53. Wang, L.; Liu, F.; Wang, A.; Yu, Z.; Xu, Y.; Yang, Y. Purification, characterization and bioactivity determination of a novel polysaccharide from pumpkin (Cucurbita moschata) seeds. Food Hydrocoll. 2017, 66, 357-364. [CrossRef]

54. Sheng, J.; Yu, F.; Xin, Z.; Zhao, L.; Zhu, X.; Hu, Q. Preparation, identification and their antitumor activities in vitro of polysaccharides from Chlorella pyrenoidosa. Food Chem. 2007, 105, 533-539. [CrossRef]

55. He, L.; Ji, P.; Cheng, J.; Wang, Y.; Qian, H.; Li, W.; Gong, X.; Wang, Z. Structural characterization and immunostimulatory activity of a novel protein-bound polysaccharide produced by Hirsutella sinensis Liu, Guo, Yu \& Zeng. Food Chem. 2013, 141, 946-953. [PubMed] 
56. Yu, Z.; Liu, L.; Xu, Y.; Wang, L.; Teng, X.; Li, X.; Dai, J. Characterization and biological activities of a novel polysaccharide isolated from raspberry (Rubus idaeus L.) fruits. Carbohydr. Polym. 2015, 132, 180-186. [CrossRef] [PubMed]

57. Wang, Y.; Yin, H.; Lv, X.; Wang, Y.; Gao, H.; Wang, M. Protection of chronic renal failure by a polysaccharide from Cordyceps sinensis. Fitoterapia 2010, 81, 397-402. [CrossRef] [PubMed] 